\title{
CONSUMO DE COMBUSTÍVEL EM DIFERENTES SISTEMAS DE PREPARO PERIÓDICO REALIZADOS ANTES E DEPOIS DA OPERAÇÃO DE SUBSOLAGEM
}

\author{
Consumption of fuel in different systems of periodical preparation performed \\ before and after the subsoiling operation
}

\author{
Nilson Salvador ${ }^{1}$, Renildo Luiz Mion², Sérgio Hugo Benez ${ }^{3}$
}

\begin{abstract}
RESUMO
Foi estudado o consumo de combustível de diferentes sistemas de preparo periódico, realizados antes e depois da operação de subsolagem num solo classificado como Nitossolo Vermelho Distroférrico. As operações de preparo foram: a) 1 aração com arado de discos; b) 1 aração com arado de discos e 1 gradagem com grade destorroadora-niveladora; c) 1 gradagem com grade aradora; d) 1 gradagem com grade aradora e 1 gradagem com grade destorroadora-niveladora e; e) 1 escarificação com escarificador. O consumo específico $\left(\mathrm{g} \mathrm{kWh}^{-1}\right)$ de combustível para os diferentes sistemas de preparo periódico do solo variou estatisticamente com a condição de subsolagem realizada antes e depois. A escarificação proporcionou menor volume de combustível requerido por hectare $\left(\mathrm{L} \mathrm{ha}^{-1}\right)$ que os demais sistemas de preparo. O preparo do solo depois da subsolagem obteve um maior volume de combustível consumido por área $\left(\mathrm{L} \mathrm{ha}^{-1}\right)$.
\end{abstract}

Termos para indexação: Preparo periódico, subsolagem, consumo de combustível.

\begin{abstract}
We studied the consumption of fuel in different systems of periodical preparation performed before and after the subsoiling operation on a soil classified as Dystroferric Red Nitosol. The systems of tillage periodic preparation were disc plowing; disc plowing followed by a light disc harrowing; heavy offset disc harrowing; heavy offset disc harrowing followed by a light disc harrowing, and chisel plowing. The specific consumption $\left(\mathrm{g} \mathrm{kWh}^{-1}\right)$ of fuel for the different systems of soil periodical preparation varied statistically with the subsoiling condition carried out before and after. The scarification resulted in a smaller volume of fuel requested by hectare $\left(\mathrm{L} \mathrm{ha}^{-1}\right)$ than the other systems of preparation. The soil preparation after the subsoiling resulted in a larger volume of fuel consumed by area $\left(\mathrm{L} \mathrm{ha}^{-1}\right)$.
\end{abstract}

Index terms: Periodical tillage, subsoiling, fuel consumption.

(Recebido em 15 de março de 2007 e aprovado em 29 de outubro de 2007)

\section{INTRODUÇÃO}

Com a necessidade de aumentar a produção de grãos no Brasil, ocorreu nos últimos tempos a abertura de novas fronteiras agrícolas e, com isso, a agricultura passou por um aumento intensivo de máquinas e implementos agrícolas no processo produtivo. Dessa maneira, todos os anos são lançados inúmeras máquinas e implementos de diferentes pesos e tamanhos, aumentando a compactação do solo.

De acordo com Machado et al. (1996), o preparo do solo vem a ser um conjunto de operações que visa a adequá-lo para o recebimento das sementes, de forma permitir o pleno desenvolvimento produtivo da cultura. Os mesmos autores enfatizam que o preparo do solo pode ser dividido em dois tipos:
O preparo primário, que são as operações iniciais de mobilização da camada de solo na qual desenvolverão as raízes das plantas, proporcionando a criação de melhores condições físicas e químicas para o crescimento delas, podendo ser executadas pelos seguintes implementos agrícolas: arados (aivecas ou discos), escarificadores ou grades agrícolas pesadas.

Preparo secundário, visa ao destorroamento e nivelamento da camada de solo que já sofreu o preparo primário, a fim de facilitar a semeadura, sendo utilizados os seguintes equipamentos: grades (dentes ou discos) e em alguns casos, os rolos destorroadores e enxadas rotativas.

De acordo com Salvador (1992), o preparo do solo raramente é efetuado baseando-se em estudos objetivos, as justificativas mais utilizadas estão no controle de plantas daninhas, manejo de resíduos vegetais, melhoria da aeração

\footnotetext{
'Engenheiro Agrícola, Doutor em Energia na Agricultura, Professor Associado - Departamento de Engenharia/DEG - Universidade Federal de Lavras/ UFLA - Cx. P. 3037 - 37200-000 - Lavras,MG - salvador@ufla.br

Engenheiro Agrícola, Doutor em Energia na Agricultura - Professor Adjunto - Departamento de Engenharia Agrícola - DENA/UFC - Universidade Federal do Ceará/UFC - Campus do Pici, Bloco 804 - Cx. P. 60455-760 - Fortaleza, CE - rmion@ufc.br

${ }^{3}$ Engenheiro Agrônomo, Doutor - Professor Titular - Departamento de Engenharia Rural - FCA/UNESP - Faculdade de Ciências Agronômicas-FCA UNESP - Faz. Lageado, Rod. Alcides Soares, Km 3 - Cx. P. 237 - 18610-307 - Botucatu,SP - benez@fca.unesp.br
} 
e porosidade do solo, preparo de um bom leito de semeadura e melhoria nas condições físicas do solo.

Hunt (1986) define o preparo periódico do solo como a atividade de inversão mecânica do solo com o propósito de permitir os cultivos. Por outro lado, Kepner et al. (1978), ao definirem o preparo periódico, usam o termo movimentação mecânica em vez de inversão mecânica do solo. Phillips \& Young (1973) afirmam que as práticas convencionais de preparo desagregam excessivamente o solo, o que pode danificar sua estrutura.

Estudando os efeitos de vários sistemas de preparo na compactação do solo e produção da cultura de milho, Benez (1972) verificou que quanto maior o número de operações de preparo, maiores foram os efeitos negativos de compactação produzida pelas rodas do trator na produção.

Mulligan et al. (1985), observaram em estudos que operações secundárias e o trafego de máquinas em excesso aumentam a densidade do solo, reduzem o crescimento das plantas e o desenvolvimento do sistema radicular.

Para Mattos et al. (1981), o gasto com combustível representa cerca de $30 \%$ do custo hora de um trator agrícola, sendo que este representa a maior parcela do custo total de uma hora de trabalho de máquina. Os custos com combustível continuam sendo um problema mundial na agricultura mecanizada, levando pesquisadores a desenvolver novos métodos de sistemas de cultivos que minimizem o uso de combustíveis (BURT et al., 1983). Concordando com estas afirmações, Fernandes et al. (2008), avaliando o consumo energético de diferentes operações agrícolas mecanizadas, concluíram que os sistemas com menos operações por hectare, obtiveram menor consumo de combustível, destacando o plantio direto, seguido do cultivo mínimo com gradagem leve, vibro escarificador e o preparo convencional, que dentre os sistemas estudados teve o pior desempenho.

No sistema tradicional, o preparo do solo é realizado depois da subsolagem, portanto, neste estudo, objetivouse avaliar diferentes sistemas de preparo periódico do solo antes e depois da operação de subsolagem.

\section{MATERIALE MÉTODOS}

O ensaio foi instalado e conduzido na Fazenda Experimental Lageado, Faculdade de Ciências Agronômicas, UNESP, Campus de Botucatu, Estado de São Paulo. A área experimental foi definida pelas seguintes coordenadas geográficas: a) Latitude Sul 22 49' 31" e Longitude Oeste $48^{\circ}$ 25'. A altitude e a declividade média são de 770 metros e 2,5\%, respectivamente. Esta área vinha sendo cultivada há vários anos com a cultura do milho, utilizando-se ininterruptamente o sistema convencional de preparo do solo (aração com disco e gradagens leves). O solo foi classificado como Nitossolo
Vermelho Distroférrico, Unidade Lageado. Os tratamentos foram delineados em blocos casualizados em esquema fatorial ( 5 x 2 com 5 repetições) com sistemas de preparo periódico: uma aração com discos (D), aração com discos mais uma gradagem de nivelamento (Dn); gradagem pesada $(\mathrm{G})$; uma gradagem aradora mais uma gradagem de nivelamento (Gn) e escarificação (E), em diferentes condições de preparo periódico do solo, antes da subsolagem (AS) e depois da subsolagem (DS), respectivamente com 5 repetições.

As características dos equipamentos utilizados são as seguintes: a) arado - de arrasto com 4 discos de $711 \mathrm{~mm}$ de diâmetro e peso aproximado de $1350 \mathrm{kgf}$; b) grade aradora - tipo "off set" com 10 discos de 812,8 mm, e peso aproximado de 3508 kgf; c) grade niveladora - tipo "off set" com 32 discos de diâmetro espaçadas de 167 mm, peso aproximado de $687 \mathrm{kgf}$; d) escarificador - montado de 10 hastes rígidas espaçadas de 250 $\mathrm{mm}$ e peso aproximado de $446 \mathrm{kgf}$; e) subsolador - de arrasto dotado de três hastes parabólicas com ponteiras aladas, espaçadas de $700 \mathrm{~mm}$, dispostas triangularmente, com peso aproximado de $710 \mathrm{kgf}$; f) trator Valmet $128 \mathrm{cv}$ (4 x 2 TDA.), lastrado, com potência de $122 \mathrm{~kW}$, peso em ordem de marcha de 6900 kgf, pneus dianteiros R-1 (14.9x26) - pressão de inflação de $95 \mathrm{kPa}$ e traseiros R-1 (18.4x34) - pressão de inflado de 110 $\mathrm{kPa}$. Durante todas as operações de campo, manteve-se a rotação do motor do trator, com carga, em $1750 \mathrm{rpm}$.

Foram utilizados os seguintes equipamentos para medição da força de tração: a) célula de carga modelo U1, precisão $\pm 0,3 \%$, capacidade de $50 \mathrm{Kn}$, fabricado pela HBM, instalada entre a barra de tração e o cabeçalho de cada implemento; b) indicador de força instantânea, modelo MVD / 2405, capacidade de 4 dígitos, precisão \pm 1 digito, fabricado pela HBM. Os aparelhos, bem como um assento para o instrumentador, foram posicionados na parte posterior do trator; c) indicador de força integrada composto de conversor de voltagem / freqüência e; d) freqüencímetro marca New Port, modelo 6220, e cronometro modelo EAA - 110 com base quartzo e precisão \pm 0,01 segundo, fabricado pela Eletronic Assembly.

O consumo de combustível foi obtido com aparelho de medição direta, denominado Pierburg, modelo PLU 106, com capacidade de registro de até $60 \mathrm{l} / \mathrm{h}$, com indicador analógico e contador eletromecânico que fornece o volume de combustível consumido por segundo. A massa especifica do óleo diesel utilizado nos ensaios foi de $887 \mathrm{~g} / \mathrm{L}$ à temperatura de $20^{\circ} \mathrm{C}$ e viscosidade média de 5,53 centepoise à $23,2^{\circ} \mathrm{C}$.

A área útil de cada parcela foi de $150 \mathrm{~m}^{2}$, isto é, $30 \mathrm{~m} \mathrm{de}$ comprimento por $5 \mathrm{~m}$ de largura. Para a determinação da força de tração requerida pelos equipamentos, do tempo gasto no percurso, do consumo de combustível, foram feitos duas determinações por parcela, exceto para a grade niveladora, nas condições AS (antes da subsolagem) e DS (depois da subsolagem). 
A força média de tração foi obtida utilizando a força integrada e o tempo gasto para percorrer trinta metros, que também foi utilizado para obtenção da velocidade de deslocamento, permitindo ainda o cálculo da potência na barra de tração.

O consumo horário de combustível foi calculado por meio das leituras feitas pelo - Pierburg - que forneceu o volume em $\mathrm{cm}^{3}$, consumido no percurso de $30 \mathrm{~m}$. Este volume foi convertido em $\mathrm{L} \mathrm{ha}^{-1}$, e no consumo especifico em $\mathrm{g} \mathrm{kWh}^{-1}$.

\section{RESULTADOS DISCUSSÃO}

Para o estudo do consumo especifico de combustível $\left(\mathrm{g} \mathrm{kWh}^{-1}\right)$, foi necessária a determinação da potência média na barra de tração. Os resultados são apresentados no Quadro 1, onde se verifica que na condição de preparo antes da subsolagem (AS), as operações com arado de discos necessitaram de mais potência do que aquelas com grade pesada e com escarificador. No preparo depois da subsolagem (DS) a necessidade de potência teve o mesmo comportamento, porém a operação de escarificação consumiu menos do que a de gradagem de nivelamento, face a atuação do escarificador como grades de dentes rígidos.

Confrontando os resultados de potência requerida para cada implemento, numa condição de preparo versus a outra, verifica-se que as operações com arados de discos e com grade niveladora foram melhores, quando executadas antes da subsolagem ou em solo firme, considerando as mesmas condições de regulagens e operacionais. Já as operações de gradagem pesada $(\mathrm{GnG})$ e de escarificação (E) necessitam de menos potência quando realizadas depois da subsolagem.

O parâmetro potência na barra é função da força na barra de tração e da velocidade operacional. $O$ operador deve, portanto, segundo Lyne et al. (1984), selecionar uma velocidade de deslocamento e rotação no motor compatíveis com as características operacionais do implemento e com a qualidade do trabalho a realizar, com o objetivo de economizar potência, pois, segundo Hunt (1986), o preparo do solo consome mais da metade da potência gasta nas propriedades agrícolas.

As operações de campo com a grade niveladora apresentaram de modo geral, o maior consumo especifico de combustível, tendo o mesmo comportamento do preparo com o escarificador depois da subsolagem (DS), que resultou em elevado consumo especifico, conforme mostra o Quadro 2. O maior consumo especifico, apresentado por esses equipamentos nessas condições de uso se deve à menor exigência de força de tração.

Relacionando o consumo especifico para cada implemento, numa condição de preparo versus a outra, observa-se que as operações de campo com arado, grade aradora e com o escarificador, proporcionaram melhor conversão energética quando utilizados antes da subsolagem, pois segundo Lyne et al. (1984), baixos valores de consumo especifico de combustível significam otimização simultânea do desempenho do motor, da eficiência trativa e da adequação implemento fonte de potência. A existência de correlação negativa entre o consumo especifico de combustível e de potência reforça essas afirmações.

Quadro 1 - Potência média na barra de tração requerida pelos implementos, em função das condições de subsolagem.

\begin{tabular}{|c|c|c|c|}
\hline \multicolumn{4}{|c|}{ Potência na Barra de Tração (kW) } \\
\hline \multirow[t]{2}{*}{ Sistemas de preparo } & \multicolumn{2}{|c|}{ Condições de preparo } & \multirow[t]{2}{*}{ Diferença $(\%)$} \\
\hline & AS & DS & \\
\hline $\mathrm{D}$ & $25,27 \mathrm{C}$ a & $27,80 \mathrm{D} \mathrm{b}$ & $-9,1$ \\
\hline Dn D & $25,26 \mathrm{C} \mathrm{a}$ & $27,72 \mathrm{D} \mathrm{b}$ & $-8,9$ \\
\hline $\mathrm{N}$ & $10,00 \mathrm{~A} \mathrm{a}$ & $13,06 \mathrm{AB} \mathrm{b}$ & $-23,4$ \\
\hline $\mathrm{G}$ & $21,24 \mathrm{~B} \mathrm{a}$ & $21,33 \mathrm{C}$ a & $-0,4$ \\
\hline $\mathrm{Gn} G$ & $21,30 \mathrm{~B} \quad \mathrm{~b}$ & $19,39 \mathrm{C} \mathrm{a}$ & 9,8 \\
\hline $\mathrm{N}$ & 10,91 A a & 14,77 B b & $-26,1$ \\
\hline $\mathrm{E}$ & $20,29 \mathrm{~B} \mathrm{~b}$ & 10,46 A a & 94,0 \\
\hline
\end{tabular}

Médias seguidas de mesma letra maiúscula na coluna e de mesma letra minúscula na linha não diferem entre si ao nível de 5\% de probabilidade, pelo teste de Tukey. 
Os resultados das analises estatísticas de consumo de combustível para os sistemas de preparo foram os mesmos, tanto numa condição de preparo quanto na outra, conforme mostra o Quadro 3. Nota-se que o sistema de preparo baseado na escarificação necessitou aproximadamente, $8,1 \%$ e $11,3 \%$ menos combustível do que os sistemas que utilizaram a aração e a gradagem pesada, antes e depois da subsolagem, respectivamente. Os sistemas de preparo que incluíram operação complementar - Dn e Gn, necessitaram de maior quantidade de combustível por hectare.

Analisando o consumo médio de combustível do preparo antes e depois da subsolagem, dentro de cada sistema de preparo, verifica-se que a realização do preparo antecedendo à subsolagem foi melhor, pois apresentou economia de combustível para os sistemas D, Dn, e Gn, como pode ser verificado no Quadro 3. Já a escarificação apresentou melhor eficiência quando realizada depois da subsolagem, onde sua função foi mais de destorroamento, pois apresentou uma redução de $33,9 \%$ no gasto de combustível.

Considerando a área de solo a ser preparada, o grau de dependência da agricultura atual em combustíveis fósseis e a participação de combustíveis e lubrificantes no custo de produção dos alimentos básicos, conclui-se que essa informação, aliada às de consumo de energia, poderão contribuir para que os empresários agrícolas tomem decisões adequadas no que diz respeito às operações de preparo periódico do solo.

Quadro 2 - Valores médios de consumo especifico de combustível nas operações com implementos, em diferentes condições de preparo.

\begin{tabular}{|c|c|c|c|}
\hline \multicolumn{4}{|c|}{ Consumo Especifico de Combustível $\left(\mathrm{g} \mathrm{kW} . \mathrm{h}^{-1}\right)$} \\
\hline \multirow[t]{2}{*}{ Sistemas de preparo } & \multicolumn{2}{|c|}{ Condições de Preparo } & \multirow[t]{2}{*}{ Diferença $(\%)$} \\
\hline & AS & DS & \\
\hline $\mathrm{D}$ & 369,9 A a & $431,1 \mathrm{~A} \mathrm{~b}$ & $-14,2$ \\
\hline $\mathrm{Dn}-\mathrm{D}$ & 369,0 A a & 441,7 A b & $-16,5$ \\
\hline$-n$ & $785,9 \mathrm{AB} \quad \mathrm{b}$ & $629,8 \mathrm{C} \mathrm{a}$ & 24,8 \\
\hline G & 420,4 A a & $500,3 \mathrm{AB} \quad \mathrm{b}$ & $-16,0$ \\
\hline $\mathrm{Gn}-\mathrm{G}$ & 416,9 A a & $526,0 \mathrm{~B} \mathrm{~b}$ & $-20,7$ \\
\hline$-n$ & $707,8 \mathrm{~B} \mathrm{~b}$ & $550,8 \mathrm{~B} \mathrm{a}$ & 28,5 \\
\hline $\mathrm{E}$ & $415,1 \mathrm{~A} \mathrm{a}$ & $641,3 \mathrm{C} \mathrm{b}$ & $-35,3$ \\
\hline
\end{tabular}

Médias seguidas de mesma letra maiúscula na coluna e de mesma letra minúscula na linha não diferem entre si ao nível de 5\% de probabilidade, pelo teste de Tukey.

Quadro 3 - Volume de combustível consumido por área, em função de sistemas e condições de preparo.

\begin{tabular}{|l|c|c|c|}
\hline \multirow{2}{*}{ Sistemas de preparo } & \multicolumn{2}{c|}{ Consumo de combustível $\left(\mathrm{L} \mathrm{ha}^{-1}\right)$} \\
\cline { 2 - 3 } & \multicolumn{2}{c|}{ Condições de preparo } & \multirow{2}{*}{ Diferença (\%) } \\
\hline D & $16,56 \mathrm{~B} \mathrm{a}$ & $20,96 \mathrm{~B} \mathrm{~b}$ & $-21,0$ \\
\hline Dn & $21,71 \mathrm{C} \mathrm{a}$ & $28,05 \mathrm{C} \mathrm{b}$ & $-22,6$ \\
\hline $\mathrm{G}$ & $16,41 \mathrm{~B} \mathrm{a}$ & $22,12 \mathrm{~B} \mathrm{~b}$ & $-25,8$ \\
\hline $\mathrm{Gn}$ & $22,13 \mathrm{C} \mathrm{a}$ & $28,59 \mathrm{C} \mathrm{b}$ & $-22,6$ \\
\hline E & $14,71 \mathrm{~A} \mathrm{~b}$ & $10,99 \mathrm{~A} \mathrm{a}$ & 33,9 \\
\hline
\end{tabular}

Médias seguidas de mesma letra maiúscula na coluna e de mesma letra minúscula na linha não diferem entre si ao nível de 5\% de probabilidade, pelo teste de Tukey. 


\section{CONCLUSÕES}

O sistema de preparo baseado em escarificação teve menor consumo especifico de combustível, quando realizado antes da subsolagem.

O preparo periódico do solo baseado em aração e gradagem pesada obteve menor consumo de combustível quando realizado antes da subsolagem.

A escarificação apresentou uma redução de 33,9\% no gasto de combustível por área de solo.

\section{REFERÊNCIAS BIBLIOGRÁFICAS}

BENEZ, S. H. Estudo do cultivo mínimo na cultura do milho (Zea mays L.) em solo Podzólico Vermelho Amarelo var. Laras. 1972. 108 f. Tese (Doutorado em Agronomia) - Escola Superior de Agricultura "Luiz de Queiroz", Piracicaba, 1972.

BURT, E. C.; BAILEY, P. W. L.; MEIRING, P. Ballast and inflation effects on tire tractive. Transactions ASAE, Saint Joseph, v. 26, n. 5, p. 1352-1354, 1983.

FERNANDES H. C., SILVEIRA, J. C. M. da, RINALDI, P. C. N. Avaliação do custo energético de diferentes operações agrícolas mecanizadas. Ciência e Agrotecnologia, Lavras, v. 32, n. 5, p. 1582-1587, set./ out., 2008.

HUNT, D. Maquinaria agrícola: rendimiento económico, costos, operaciones, potência, y seleccion de equipo. 7 . ed. México: Limusa, 1986. 451 p.
KEPNER, R. A.; BAINER, R.; BARGER, E. L. Principles of form machinery. 3. ed. Westport: Avi, 1978. 527 p.

LYNE, P. W. L.; BURT, E. C.; MEIRING, P. Effect of tire and engine parameters on efficiency. Transactions ASAE, Saint Joseph, v. 27, n. 1, p. 5-11, 1984.

MACHADO, A. L. T.; REIS, A. V. dos; MORAES, M. L. B. de; ALONÇO, A. dos S. Máquinas para preparo do solo, semeadura, adubação e tratamentos culturais. Pelotas: [s.n.], 1996. 229 p.

MATTOS, P. C.; HERMANN, P. R.; CAPELLI, N. L. Estudo comparativo de desempenho do trator agrícola empregando óleo diesel e mistura de etanol/óleo de mamona como combustíveis. In: CONBEA, 11., 1981, Brasília, DF. Anais... Brasília, DF, 1981. p. 1083-1085.

MULLIGAN, M. F.; SMUCKER, A. J. M.; SAFIR, G. F. Tillage modifications of dray edible bean root colonization vamfungi. Agronomy Journal, Madison, v. 77, n. 1, p. 140-144, 1985.

PHILLIPS, H.; YOUNG, H. M. Agricultural sim laboreolabranza cero. Traduzido por E. Marchesi. Montevideo: Hemisfério Sur, 1973. 223 p. Título original: No-tillage farming.

SALVADOR, N. Consumo de energia na operação de subsolagem realizada antes e depois de sistemas de preparo periódico do solo. 1992. 166 p. Tese (Doutorado em Agronomia) - Universidade Estadual Paulista, Botucatu, 1992. 